\title{
SABERES ANCESTRALES Y PRÁCTICAS TRADICIONALES: EMBARAZO, PARTO Y PUERPERIO EN MUJERES COLLA DE LA REGIÓN DE ATACAMA
}

\author{
ANCESTRAL KNOWLEDGE AND TRADITIONAL PRACTICES: \\ PREGNANCY, CHILDBIRTH, AND PUERPERIO IN WOMEN COLLA \\ OF THE ATACAMA REGION
}

\author{
Viviana Rodríguez Venegas ${ }^{*}$ y Cory Duarte Hidalgo**
}

\begin{abstract}
Etnografía feminista que indaga en los saberes ancestrales y las prácticas de cuidado transmitidas intergeneracionalmente por mujeres colla de la región de Atacama, Chile, en virtud de las etapas vitales del embarazo, parto y puerperio. Los resultados del estudio revelan que son conocimientos encarnados en los cuerpos, oralidades y experiencias de mujeres colla, transmitidos matrilinealmente mediante una sólida red familiar y comunitaria, situados en el territorio atacameño, apegados a las costumbres y tradiciones culturales propias de su pueblo.

El proceso investigativo reconoce la profunda sabiduría ancestral de la medicina indígena colla, recuperada por medio de la memoria larga de las mujeres indígenas, fundamentada tanto en el compartir saberes y prácticas en salud y nutrición como el parir y criar en virtud de su historia y cultura. Las mujeres colla ponen en el centro los cuidados del cuerpo y la maternidad colectiva, la preservación de la ancestralidad y la desmedicalización de los procesos femeninos, transformándose así en su principal estrategia de resistencia cultural descolonizadora.
\end{abstract}

Palabras claves: Mujer indígena, pueblo colla, medicina ancestral indígena.

Feminist ethnography investigates ancestral knowledge and care practices transmitted intergenerationally by Colla women in the Atacama region, Chile, under the vital stages of pregnancy, childbirth, and the puerperium. The study results reveal that they are knowledge embodied in the bodies, oralities, and experiences of Colla women, transmitted matrilineally through a stable family and community network, located in the Atacameño territory, attached to the customs and cultural traditions of their people.

The research process recognizes the deep ancestral wisdom of indigenous colla medicine, recovered through the long memory of indigenous women, based on both sharing knowledge and practices in health and nutrition, and giving birth and raising their children under their history and culture. Colla women put body care and collective motherhood, preserving ancestrality and demedicalization of female processes at the center, thus becoming their foremost decolonizing cultural resistance strategy.

Key words: Indigenous woman, Colla people, indigenous ancestral medicine.

\section{Introducción}

Los saberes ancestrales tradicionales de las mujeres respecto del embarazo, parto y puerperio son prácticas vitales transmitidas intergeneracionalmente, enfocadas en el bienestar físico, emocional, espiritual y comunitario de la mujer y de quien nace.

En el mundo indígena, los cuidados de las mujeres se viven como un entramado de prácticas culturales y de relaciones sociales e interétnicas destinadas a sostener la vida, enmarcadas en un conjunto de normas sociales y culturales que definen elementos que les son permitidos en dichas etapas, destacando rigurosas pautas de alimentación, prohibición de participar en ciertos eventos sociales y otras de orden inmaterial como la prevención del encuentro con determinados espíritus (Alarcón y Nahuelcheo 2008). Es decir, los saberes y prácticas asociadas al cuidado de las mujeres durante este período vital, trascienden lo biológico para transformarse en un fenómeno social y cultural.

No obstante, el modelo biomédico considera al parto, embarazo y puerperio como procesos universales y asépticos, sin tomar en consideración las diversas corporalidades y territorialidades. Por el contrario, los procesos vitales en los pueblos indígenas contienen prácticas y conocimientos de la medicina ancestral, encarnados en cuerpos, oralidades y experiencias de mujeres -según nuestro caso-que son transmitidos y valorados intergeneracionalmente.

\footnotetext{
* Universidad de Atacama, Departamento de trabajo social, Copiapó, Chile. Correo electrónico: viviana.rodriguez@uda.cl

** Universidad de Atacama, Departamento de trabajo social, Copiapó, Chile. Correo electrónico: cory.duarte@uda.cl
} 
El trabajo investigativo que se presenta en este artículo considera a las mujeres colla como "creadoras culturales", lo que permite elaborar un vínculo integrador entre lo material, lo subjetivo, el poder, la agencia y la situación/condición de las mujeres (Castañeda 2010). En ese sentido, como investigadoras ocupamos un lugar (Favret-Saada 1990), en un sistema de relaciones que nos habilitó a conocer dicho mundo social, permitiendo producir "conocimientos situados" (Haraway 1991), cuestionar las relaciones de poder en el trabajo de campo, definiendo definir nuestro "lugar de enunciación" (Ribeiro 2018) y asumir un posicionamiento desde lo ético y político, que implicó "poner el cuerpo" (Castañeda 2019).

En este sentido, la presente etnografía feminista expone estas prácticas y saberes en los territorios que habitamos, desde y con las mujeres colla, quienes ponen en el centro los cuidados del cuerpo y la maternidad colectiva, la preservación de la ancestralidad y la desmedicalización de los procesos femeninos, transformándose así en su principal estrategia de resistencia cultural descolonizadora.

\section{Algunas tensiones y elementos contextuales respecto del pueblo y las mujeres colla}

El pueblo colla se ha establecido en el territorio atacameño desde hace casi dos siglos, caracterizándose por los continuos intercambios desarrollados entre las localidades cordilleranas y la puna. Es un pueblo trashumante, apegado a la naturaleza y sus ciclos, que transita espacios considerados adversos, deshabitados (Molina 2014) y que hoy son reconocidos como territorios en sacrificio.

En los estudios publicados observamos dos visiones acerca del pueblo colla: por un lado, la existencia de un relato escrito que excluye a las mujeres y, por otro, la amenaza del avance de la industria extractivista en sus territorios.

En relación con el primer asunto, hemos señalado que la construcción de lo colla se ha realizado desde una mirada androcéntrica de la historia, con base en estereotipos masculinizados (Rodríguez y Duarte 2018), derivados de representaciones ligadas a la actividad económica o mercantil (Gleisner y Montt 2014; Molina 2014), sin dejar espacio a las acciones que desarrollan las mujeres. De esta forma, las descripciones del quehacer y cosmovisión del pueblo colla están permeadas por un modelo único y homogéneo relacionado con lo que es o debería ser el hombre adulto joven perteneciente a dicho pueblo. Al mismo tiempo, se ha construido una imagen esencializada de la mujer colla, ubicándola en un segundo o tercer plano, dejando de lado su historicidad y capacidad de agencia, estructurando trayectorias sociales en donde las mujeres están ausentes. Estos relatos niegan y subalternizan sus vidas, invisibilizándolas, excluyendo su responsabilidad en la restitución de movimiento y construcción de memoria. No obstante, el protagonismo de las mujeres es innegable sobre todo en los procesos de etnogénesis y reetnificación del pueblo colla (Rodríguez y Duarte 2018).

El otro elemento observado tiene relación con las territorialidades y su afectación por parte de implicancias externas. Durante el siglo XX, las comunidades colla vivieron el proceso de chilenización, tal y como sucedió con otros pueblos andinos (Caroselli 2013). La pérdida de identidad resultante de dicha fase se entremezcla con el despojo de las tierras y su lengua, el exilio y la obligación de reconvertir las ocupaciones tradicionales con tal de incorporarse como mano de obra en rubros como la minería o el sector agrícola. De esta forma, se desarrollaron varios ciclos de apropiación y control del territorio colla, ya sea por la acción estatal o por la privatización de las tierras (Gundermann 2018), los que están profundamente marcados por el conflicto, debido a las asimetrías en el poder entre los distintos actores inmiscuidos (Lorca y Hufty 2017).

En la actualidad, en el territorio que es transitado por el pueblo colla, existen cinco conflictos socioambientales (Instituto Nacional de Derechos Humanos [INDH] 2018); al mismo tiempo, se localizan al menos seis faenas mineras con proyectos pertenecientes a transnacionales de capitales canadienses que operan por intermedio de filiales chilenas (Guerra 2018). Los proyectos instalados en el territorio colla extraen, en su mayoría, oro, plata y cobre, generando fragmentaciones territoriales (Gudynas 2011) y modificaciones en los ciclos del pueblo, pues afectan terrenos que tradicionalmente se usaban en el pastoreo (Molina 2014). Estas situaciones desembocan en una migración forzada, pues las comunidades han modificado "sus modos de vida ancestrales, sus rutas de trashumancia y sus costumbres más propias" (INDH 2019: 36). Lo anterior, genera tensiones debido a las distintas estrategias utilizadas por las industrias extractivistas para llegar a acuerdos con las comunidades indígenas, existiendo en algunos casos, presiones 
y persecuciones, en un contexto en el que el Estado no protege ni garantiza el derecho a vivir en un ambiente libre de contaminación y la preservación de la naturaleza, elementos esenciales en las prácticas culturales y cosmovisión del pueblo colla.

\section{Elementos que facilitan la comprensión del tema de estudio}

Las prácticas y saberes asociados a los ciclos naturales de las mujeres tales como el embarazo, parto y puerperio, han sido controlados por el modelo biomédico de salud, desde una mirada fisiológica, basada en lo reproductivo, caracterizado por el etnocentrismo, la colonización y la asimetría (Dias-Scopel et al. 2017). No obstante, existen ciertas prácticas de autocuidado en salud que dan cuenta de intermediaciones entre la medicina occidental y el mundo indígena (Dias-Scopel et al. 2017), integrando prácticas y saberes que permiten la resistencia y sobrevivencia de las comunidades.

La mirada que los pueblos indígenas poseen respecto de la salud representa "una convivencia armónica del ser humano con la naturaleza, consigo mismo y con los demás hacia un bienestar integral" (Chávez et al. 2007: 681), de tal manera que, cuerpo, territorio y ambiente se integran en las prácticas que la población indígena desarrolla en el cuidado de la salud (Dias-Scopel et al. 2017). Los pueblos indígenas, acorde con sus tradiciones ancestrales, poseen varias normas y procedimientos internalizados mediante procesos de socialización ajenos al control de los equipos de salud (Dides y Pérez 2007). En este sentido, se identifican diversos saberes y prácticas propias de los mundos indígenas, en los que se encuentran disposiciones acerca del cuidado del agua, los cuerpos, los ciclos vitales y la autoatención en salud (Dias-Scopel et al. 2017), creencias y saberes que coexisten con miradas occidentalizadas, transmitidas transgeneracionalmente (Chávez et al. 2007), esenciales para la preservación de la vida (Alarcón y Nahuelcheo 2008) y que están cultural e históricamente situados.

No podemos dejar de enunciar las condiciones de inequidad que viven las mujeres indígenas en materias de salud sexual y reproductiva en todo el continente producto de la discriminación estructural que existe en nuestras sociedades (Mendoza et al. 2013). Ello es observable tanto en los indicadores de embarazo adolescente, muerte en el parto o número de hijos/as, pero también, y en lo cotidiano, se aprecia en el establecimiento de actuaciones racializadas como formas de demarcación de la alteridad (Baeza 2013). Este es un elemento a considerar debido a que las mujeres indígenas generan estrategias de resistencia y de intermediación al interactuar con los equipos médicos, en procesos de adaptación al modelo hegemónico, lo que implica la pérdida paulatina de los conocimientos, prácticas y creencias (Alarcón y Nahuelcheo 2008).

\section{Metodología}

La investigación tiene como principal objetivo el indagar en los saberes ancestrales y las prácticas de cuidado transmitidas intergeneracionalmente por mujeres colla de la región de Atacama, Chile, en virtud de las etapas vitales del embarazo, parto y puerperio. Para tal propósito, se realiza una etnografía feminista que reconoce durante todo el desarrollo del estudio, formas particulares de conocimiento situado.

El trabajo de campo se desarrolló entre el 2015 y 2018, período en el que, por medio de una muestra teórica, se estableció contacto con mujeres autodenominadas colla, de edades fluctuantes entre 20 y 70 años, con liderazgos formales e informales, madres de un promedio de tres hijos/as y cuentan con experiencias personales o familiares con parteras colla.

Respecto de las técnicas de recopilación de información, se utilizaron al menos cuatro, en distintos momentos de la investigación. Destaca la ejecución de entrevistas en profundidad, realizadas cara a cara en una o dos sesiones, de 90 minutos, aproximadamente, a 12 mujeres colla de las comunidades indígenas Tierra Viva, Comunidad Colla, El Torín, María Luisa Trejo, Inti Wañuy, Consejo Nacional Indígena ATYPAMUY y Manta Tujsi Wayra, ubicadas en las comunas de Copiapó, Tierra Amarilla, Caldera y Diego de Almagro de la región de Atacama, Chile. La gran mayoría de las entrevistas se realizaron en su ámbito cotidiano, en sus hogares, mientras realizaban las labores del hogar, cocinaban o ejercían labores de cuidado, vinculando así la observación participante de las costumbres y prácticas asociadas al cuidado. Igualmente, en otras ocasiones nos reunimos en el espacio público, cuando no fue posible realizar las entrevistas en sus hogares, lo que implicó una cálida manera de "habitar" juntas el territorio. En cada uno de los encuentros se efectuaron notas de campo en las que se recabaron relatos sociohistóricos, autobiográficos, 
recetas de cocina, remedios con hierbas medicinales $\mathrm{y}$ algunas precisiones técnicas para el cuidado al recién nacido. Adicionalmente se realizaron dos grupos de discusión, valiéndose de la motivación de las participantes en compartir dichos saberes, los que fueron realizados en las comunidades María Luisa Trejo e Inti Wañuy.

La información recopilada fue transcrita e ingresada al software de datos cualitativos Atlas. Ti, versión 8, lo que permitió sintetizar y ordenar la totalidad de la información, para posteriormente proceder a la comparación y codificación abierta a base de tres categorías: parto, embarazo y puerperio. Esta etapa se realizó por medio del análisis de contenido (Krippendorff 1990).

La investigación consideró ciertos resguardos éticos, entre los que destacan: informar los objetivos, procedimientos y participación requerida por el estudio; asegurar que la participación en el estudio no involucrase ningún daño o peligro para la salud física o mental; uso del consentimiento informado individual; garantizar la voluntariedad y posibilidad de desvincularse en cualquier momento; entre otros. Igualmente, se utilizó grabación de audio, información que fue tratada y almacenada confidencial y anónimamente. Así también, se consideró la devolución de información de manera participativa $\mathrm{y}$ activa durante todo el proceso investigativo.

\section{Resultados}

\section{Embarazo en las mujeres colla: cuidados y ancestralidad}

El embarazo es una etapa de cuidado y contención para las mujeres colla. En ella se inicia la organización de la red de apoyo que acompañará a la mujer en un proceso vital que finaliza con el destete, el que ocurre cerca de los dos años. Los saberes de la salud y nutrición son transmitidos de manera matrilineal, apegándose a las tradiciones culturales propias de su pueblo.

La nueva criatura se espera con ansias, sin importar las condiciones, pues es parte de la familia y comunidad. De esta forma, las mujeres se muestran independientes y orgullosas de su maternidad sin necesidad de depender económica o emocionalmente de alguien.

mi abuela, ella falleció señorita, nunca se casó, pero tenía once hijos y ella sola con sus hijos (...) nos enseñó a todos nosotros a criar y a ella nunca se le preguntó dónde está el papá (...) nada de eso, ella sola con sus hijos...y yo también soy mamá soltera nunca he necesitado a un hombre (45 años, comunidad María Luisa Godoy Trigo, Copiapó).

Los cuidados se dirigen a aspectos como la alimentación y la actividad física, existiendo prohibiciones para evitar esfuerzos por parte de la embarazada, ya que las mujeres en el mundo colla realizan labores en el campo (pastoreo) para la subsistencia familiar.

En el mundo andino es importante mantener el calor en el vientre, para ello se visten con una prenda de lana roja, un calzón, como forma de protección, y abrigan la espalda para asegurar la producción de leche. Varias de ellas indicaron algunas recomendaciones y normas pertinentes a la alimentación durante el embarazo, las que están relacionadas con los nutrientes a ingerir para preservar la salud de la guagua y poder amamantar. El consumo de caldos de gallina o "guatitas" [sopa de estómago de res], así como el consumo de avena, son recomendados a las embarazadas:

la mamá le tenía que hacer un caldo de gallina negra (...) entonces cuando una estaba embarazada, criaban una gallina negra todo el periodo. Llegaba el momento que tenían la guagua y le daban caldito de gallina (57 años, comunidad Manta Tujsi Wayra, Copiapó).

\section{Parto colla: entre la añoranza de sus tradiciones y la reexistencia de saberes y prácticas de la medicina ancestral colla}

La preparación del parto es muy importante en la cultura colla. Es un momento en el que las embarazadas reciben cuidados y ejecutan las prácticas que se transmiten de generación en generación, como saberes ancestrales. Una de aquellas costumbres es la realización de vahos con manzanilla, los que se realizan en un ambiente cálido, en el que se hierve un litro de manzanilla y se vierte en un lavatorio o bacinica, las embarazadas se sientan abrigadas para que pase el vapor hacia el útero. Posteriormente, las mujeres descansan unos minutos, mientras las acompañantes les dan masajes y friegas en la panza. 
Las "agüitas de monte" son fundamentales, ya que ayudan a las embarazadas a relajarse y a apurar el nacimiento del bebé:

cualquier tipo de agüita de hierbas que fuera relajante, que fueran $\mathrm{pa}^{\prime}$ que la guagua saliera rápido, la salvia, la hierba lincordia, algún tipo de menta y manzanilla (61 años, comunidad Inti Wañuy, Caldera).

Otro aspecto característico en la etapa final del embarazo es el empleo de la técnica conocida como "mantear", la que es utilizada cuando "la guagüita viene mal encajada", mediante movimientos específicos realizados por mujeres conocedoras de esa práctica.

es una técnica pa' apurar al bebé. Mira, se tira arriba de un poncho o de una manta, pescan de las cuatro esquinas y la levantan $\mathrm{pa}^{\prime}$ arriba como ese pescadito que a uno le hacían en la escuela, entonces, donde seguro que las mujeres sienten el vacío, la guagua se pega la acomodá y eso ha resultado (42 años, comunidad Tierra Viva, Tierra Amarilla).

El momento del parto es un marcador de tensiones entre el mundo colla y el sistema biomédico. Las entrevistadas mencionan que no han tenido la oportunidad de realizar partos tradicionales en sus hogares. Por ello, el parto en los centros hospitalarios es recordado como una experiencia violenta, en la que distinguen elementos de discriminación y de desconexión con sus tradiciones. El parto en casa, según las mujeres, es una práctica clandestina, perseguida y prohibida por el sistema médico-legal.

Ahora el tema sanitario es muy complicado, o sea nadie pasa piola [desapercibida] que estuvo embarazada y no parió en el hospital, por el tema de la inscripción y muchas cosas, papel de parto y todo (47 años, comunidad Colla, Diego de Almagro).

Esta sensación de prohibición, de estar haciendo algo que está fuera de la ley, les expone a riesgos y a no cumplir con la tradición de acompañamiento colectivo, en el que se vive el cuidado de otras mujeres.
Parió en el campo, sola y se metió a uno de estos cuartuchos que guardaban las herramientas y ahí parió en cuclillas arriba de un cuero y me parece que todos los hijos los ha parido así (42 años, comunidad Tierra Viva, Tierra Amarilla).

El parto tradicional colla tiene sus bases en la cosmovisión andina, por lo que se enfatiza la importancia de la organización comunitaria por sobre las individualidades, el contacto íntimo y cercano entre la pareja y sus familiares, su conexión con el entorno y el respeto por la dignidad de la mujer. El parto tradicional se caracteriza por realizarse en casa, acompañada de otras mujeres de la familia, quienes colaboran para que la mujer, al momento de parir, se ponga en cuclillas sobre un cuero, asemejándose a las cabras.

Las parteras ocupan un lugar importante en la configuración que el pueblo colla hace del proceso de parto, siendo este un oficio tradicional, humanizado y respetado. Las mujeres cuentan que algunas de ellas o sus madres fueron atendidas por parteras, sin embargo, la tradición se rompe en las generaciones actuales, debido a que quienes se dedicaban a estos menesteres han envejecido o fallecido, casi extinguiéndose la práctica.

yo he escuchado de parteras en el campo (...) hay gente que todavía se atiende con parteras o sea hay personas que saben hacer el trabajo a lo mejor un poco más modernizado que antes, pero las parteras como bien profesional (...) mi mamá me contó porque yo de los cuatro hijos que tuvo mi mamá la única que nací con partera (...) y resulta que las señoras eran como verdaderas matronas, sabían muy bien todo lo que estaban haciendo y eran prácticamente profesionales en su quehacer (45 años, comunidad María Luisa Godoy Trigo, Copiapó).

En la actualidad, la opción de parir de la forma tradicional se levanta con fuerza. Las mujeres colla solicitan un trato diferenciado que incluya a las parteras, pues son un apoyo vital en el proceso de parto tradicional.

Una vez ocurrido el parto, la abuela se preocupa de bañar al bebé y mostrarlo al resto de la familia, mientras que la partera se ocupa de atender a la 
madre. Posteriormente, la placenta es entregada al padre del bebé, o quien sea considerado para esta labor. La persona encargada del cuidado de la placenta la entierra, acto en el que agradece a la Pachamama por el nacimiento de un niño o niña, fuerte, vigorosa y llena de vida.

me contó mi mamá que cuando yo nací, mi papá enterró su placenta, así se devolvía a la tierra (...) mira yo le preguntaba a mi papá, pero me parece que se enterraba a la ubicación del naciente (57 años, comunidad Manta Tujsi Wayra, Copiapó).

\section{Cuidados colectivos en el puerperio: sanando a la madre y criando al recién nacido}

El puerperio para las mujeres colla es una etapa trascendental, llena de cambios tanto para la mujer como para el recién nacido. En esta etapa se les asigna un cuidado especial, en el que es esencial la compañía familiar y soporte comunitario, otorgando la protección necesaria en aspectos como la salud y la nutrición. Respecto de los cuidados de la mujer, el consumo de agüitas de monte ayuda a limpiar y ordenar su organismo. Igualmente, explican que hay hierbas que poseen propiedades para combatir lo que es definido como depresión postparto, la que identifican como un problema estacional. Este período se inicia en el parto y culmina con la normalización del organismo femenino, el que dura dos años aproximadamente. Cuando el niño o la niña comienza a caminar, la mujer también se "independiza".

nosotras no le llamamos así a la depresión postparto. Eso son nombres médicos (...) se les debe sanar el corazón no las depresiones en las mujeres. Debe ser tratado con hierbas medicinales más que recurrir a los medicamentos. Les digo yo que la salvia cura el alma, el aura, es antiinflamatoria, es depurativa, es analgésica, las tiene todas, desinfectante, cicatrizante, es una planta sagrada (57 años, comunidad Manta Tujsi Wayra, Copiapó).

Las heridas de las cesáreas son limpiadas y curadas con hierbas medicinales; para las várices se aconseja utilizar cataplasmas y cremas hechas con caspiche y matico, se recomienda el uso de fajas para "que la matriz no se soltara" y el debido respeto de la "cuarentena".

La alimentación es trascendental para las mujeres en la etapa de puerperio, pues "deben retomar energías". Se desaconseja la ingesta de alimentos que pueden afectar la lactancia y se alienta el consumo de otros que permiten reponerse a la madre.

después del parto venía la dieta, un buen caldo de cordero, el caldo de gallina negra bien cargado pa' que no parieran tan seguido $\mathrm{y}$ a la guagua media cucharada de caldo pa que tuviera estómago (65 años, comunidad El Torín, Tierra Amarilla).

La ingesta de caldos es recomendada para reponer la energía gastada durante el parto, es por ello que, cuando las mujeres quedan muy débiles, se les aconseja hervir o tostar cáscaras de huevo,

triturarlas finamente, se toma leche con cáscaras de huevos molidas muy finamente y acompañadas con leche, para incrementar de esta manera el consumo de calcio y te daban hígado para recuperar la sangre (45 años, comunidad María Luisa Godoy Trigo, Copiapó).

Durante el puerperio, es fundamental el apoyo de las madres, tías, comadres y abuelas, ya que son las que asisten a la "recién parida" y cuidan al bebé de manera unida y comunitaria; sabiendo que la madre está en proceso de recuperación.

En este período existen tensiones con el sistema biomédico, ya que las indicaciones que han recibido intergeneracionalmente, incluyen prácticas que son desaconsejadas por el personal sanitario.

mi hija tuvo la guagua a las once de la noche, al otro día llegué a la visita con una viandita de caldo de gallina negra pa' ella y a la guagua, le di el caldo delante de la enfermera, la enfermera me dijo: la vas a matar y le dije: No, todos nosotros hemos tomado caldos. Al otro día le traje al tiro [inmediatamente] un pato [biberón] lleno de caldo pa' la guagua (57 años, comunidad Manta Tujsi Wayra, Copiapó).

Las mujeres mencionan que amamantar es un método anticonceptivo, para ello promueven 
esta práctica tanto para la alimentación saludable del recién nacido como para evitar los embarazos, usando a la par las plantas medicinales.

\section{Discusión}

El estudio indica que las prácticas y saberes asociados al embarazo, parto y puerperio de mujeres colla están situados al territorio y a sus costumbres, circunscritas al establecimiento de una sólida red familiar y comunitaria, la que se establece para la entrega de soporte, acompañamiento y cuidados. Estos saberes están asentados en la medicina tradicional indígena en donde la oralidad intergeneracional es relevante para la preservación de las relaciones sociales y comunitarias, pero también para la conservación de "la vida, la armonía, el equilibrio y el bienestar del pueblo indígena" (Cardona-Arias 2012: 476). En este sentido, la oralidad de las prácticas es relevante para la transmisión y preservación de la memoria colectiva (Arévalo 2012), siendo este un punto crucial, pues el pueblo colla ha perdido su lengua originaria (Gálvez 2012), estableciéndose un hablar abigarrado, por lo que la transmisión del patrimonio inmaterial es acción de permanente resistencia, no siempre consciente, en el que el ejercicio de las prácticas tradicionales es vivenciado de modo subalterno. Lo anterior, en el caso que aquí se presenta, tiene conexión con la relación conflictiva entre saber hegemónico y saber indígena, pues estos últimos se basan en conocimientos configurados a partir de la cosmovisión y cosmogonía andina, los que se encuentran en tensión permanente con los procesos clientelares de salud y la medicalización de la medicina occidental.

En la medicina indígena "el proceso saludenfermedad-atención es culturalmente definido y está direccionado a prevenir y curar la enfermedad, y restaurar y preservar la salud, empleando las plantas medicinales como principal recurso terapéutico" (Cardona-Arias 2012: 639-640), de esta forma, las personas indígenas idóneas, por medio de los elementos de la naturaleza, ríos, plantas y animales, actúan "como intermediario entre la madre naturaleza y el paciente, al activar la relación con la madre naturaleza" (Cardona-Arias 2012: 476). Por tanto, "el contacto con la naturaleza es estrecho y permanente, la renovación significativa a la que nos referimos es controlada en cada acto, como lo ha sido siempre, porque de eso depende la "salud" de los vínculos coexistenciales" (Gudemos 2012: 10), lazos que unen cuerpos, parentescos, comunidades, ritos y costumbres.

Por su parte, el sistema biomédico "divide la naturaleza humana en cuerpo y mente, y el cuerpo es considerado como una estructura biológica" (Baeta 2015: 82), que reducen las "concepciones biomédicas del cuerpo como una entidad total y unitaria, representativas de un monismo biológico a-relacional"(Bonelli 2015: 11). Por tanto, la salud es entendida como un concepto científico apolítico, ahistórico y acultural que homogeneiza a las personas, construyendo estereotipos de lo que es o no normal (Navarro 1998; Alcántara 2008; Briceño-León 2000), generando el riesgo de fomentar la discriminación y prejuicio a ciertos grupos (Alcántara 2008).

La medicina ancestral indígena y el sistema biomédico están en una constante tensión paradigmática en la que se ponen en discusión saberes epistémicos, la naturaleza del ser humano y los valores axiológicos. Con estas tensiones en juego, las mujeres colla identifican dificultades e impedimentos para el desarrollo de prácticas culturales asociadas a las etapas del embarazo, parto y puerperio. Ello está ligado a hechos de violencia y discriminación, pues persiste la mirada institucionalizadora y etnocéntrica propia del enfoque sanitario occidental, el que generalmente centra los cuidados culturales en la disminución de la morbimortalidad materno perinatal por partos realizados fuera de los recintos hospitalarios (Organización Panamericana de la Salud, s.f), ello hace que no se propicie el entender y mantener los saberes, usos y costumbres indígenas asociados al cuidado de la vida y la reproducción, lo que implica la desvalorización de las prácticas y saberes indígenas como partes de un sistema médico necesario de preservar (Chávez y Carpio 2018), lo que deriva en la prevalencia de un discurso hegemónico que deslegitima la medicina tradicional indígena ancestral. Lo anterior es observado en el caso de las parteras colla, las que, por el envejecimiento, el temor a las represalias y la imposición del modelo médico occidental, están casi extintas formalmente. La fuerza colonizadora evalúa y etiqueta los saberes científicos y verdaderos, estando los demás envueltos en la confusión, situados desde lo mágico y lo mítico; por ello, los saberes indígenas, comunitarios y populares siguen siendo considerados exóticos e irrelevantes, prohibidos en su práctica y circulación.

El saber indígena se relaciona con la cultura, identidad, territorio y el desarrollo sustentable de 
las comunidades, mediante la autogestión de recursos vegetales/naturales y prácticas tradicionales con fines medicinales, los que están en constante amenaza por la racionalidad económica del proceso globalizador (Bañuelos y Salido 2007). Se suma a ello el abandono gubernamental, lo que ha generado consecuencias negativas en el uso y preservación de los conocimientos ancestrales y el medio ambiente de los pueblos indígenas, campesinos y rurales (Jiménez et al. 2015; Bañuelos y Salido 2007). En este contexto, es crucial escuchar y practicar la herencia de nuestros ancestros y ancestras, en una cosmovisión emergente que pretende reconstituir la armonía y el equilibrio de la vida con la que convivieron generaciones pasadas, y que ahora es la respuesta estructural de los pueblos indígenas frente al extractivismo y la neocolonización (Huanacuni 2010). No obstante, los pueblos indígenas, mediante sus sistemas de saberes, valores, conocimientos, organización social y productiva, fueron y siguen siendo protagonistas en las estrategias de preservación de la tierra y sus recursos, por lo que "constituyen el patrimonio de recursos naturales y culturales" (Leff et al. 2002: 494); de esta forma, son fuente de aprendizaje, en el que se debe fortalecer el intercambio y diálogo de saberes en todos los ámbitos de la vida, incluyendo el cuidado de la vida y la reproducción. Es necesario reafirmar que, este diálogo de saberes y prácticas, deben darse en condiciones de horizontalidad y complementariedad en el que se respeten los conocimientos y se generen espacios de confianzas (Hansen 2012), en los que se consideren las trayectorias, memorias, contextos e historia (Baeta 2015).

Las mujeres colla recuperan la memoria larga de sus propios cuerpos racializados, tanto en el compartir saberes y prácticas como en el seguir pariendo y criando con base en su historia y cultura; por tanto, recuperan prácticas que reivindican los saberes indígenas, acuerpados en las mujeres, prácticas micropolíticas que representan una vía de escape permanente, viviendo en los márgenes una política de subsistencia y resistencia (Rivera Cusicanqui 2018). Esto es manifestado por las mujeres colla en ciertas conductas y relaciones que se establecen en distintas espacialidades, desde el acuerpar, "poner el cuerpo, hacerlo en un encuentro de comunidades de afectos" (Rivera Cusicanqui 2018: 73). Se acuerpan los saberes mediante prácticas de resistencia no siempre conscientes, que preservan en la memoria colectiva, y que implican formas colectivas de cuidado. De esta forma, las mujeres recuperan el cuerpo "para defenderse del embate histórico estructural que atenta contra él" (Cabnal 2010: 22) situándose en la práctica de una micropolítica en el contexto de las epistemologías del sur, implica revalorar los saberes y prácticas de las abuelas, de las ancestras, de tal forma que se "las nombra, las reconoce y legitima su conocimiento, resistencias y sabidurías" (Cabnal 2010: 24).

La mantención de estos saberes ancestrales y prácticas tradicionales del embarazo, parto y puerperio de las mujeres colla son acciones desde la "micropolítica" que permiten cuidar el territoriocuerpo, amarse entre mujeres, cuidar la vida y con ello, todo el ecosistema que las rodea. Lo anterior permite la preservación, valoración y transmisión de estas prácticas propiciando la sobrevivencia simbólica y cultural del pueblo colla.

\section{Conclusiones}

Este estudio demuestra la memoria viva de las comunidades indígenas y sus sistemas médicos tradicionales, en particular los conocimientos y prácticas asociados al cuidado de la salud de la mujer indígena en su función más sagrada: la reproducción de la vida.

En ello, las mujeres indígenas de América Latina y el Caribe con diversas acciones y actividades diarias promueven la defensa y protección de comunidades, territorios, recursos naturales y de todo el ecosistema viviente que en ellas cohabitan. En sus saberes ancestrales de plantas medicinales, ciclos lunares y solares, el cuidado corporal, espiritual y comunitario, su puesta en valor por la reproducción y la sostenibilidad de la vida, se convierten en armas de resistencia cultural descolonizadora para combatir al modelo desarrollista y neoextractivista que impera con fuerza en toda la región, que cada día se vuelve más violento y mortal.

En este escenario, las mujeres colla de la región de Atacama tienen el desafío de reivindicar sus conocimientos y prácticas por medio de sus cuerpos, identidades y cultura, que han sido históricamente desplazados por los saberes y poderes hegemónicos, con la convicción de revertir sus condiciones sociales que las ubican en lugares de subalternidad y de violencia patriarcal.

La línea divisoria que separa los saberes y prácticas occidentales de los pueblos indígenas demuestra la clara injusticia de negar la sabiduría 
ancestral, manteniendo la supremacía de la modernidad científica y la mantención de un Estado uninacional y monocultural. Las mujeres generan resistencias desde la "micropolítica", acuerpadas en el cuerpo-territorio que se materializa en la preservación y transmisión de los saberes ancestrales y prácticas tradicionales en el embarazo, parto y puerperio de generación en generación, asociadas al uso de hierbas medicinales, utilización de friegas, masajes, vahos, manteos, identificar el tipo de alimentación y los cuidados a las mujeres en estas etapas vitales, desmedicalización de los procesos femeninos, el (re)posicionamiento de las parteras $\mathrm{y}$ un profundo respeto por la medicina tradicional ancestral.

Es importante destacar que este prolongado ejercicio investigativo forjó una alianza sorora que ha conducido a mantener lazos de consejería y apoyo mutuo en las coyunturas locales y regionales. Lo que ha servido para potenciar la capacidad de agencia, circular la palabra, fortalecer liderazgos y redes de acción, articular a las mujeres indígenas y las colectivas feministas, develar y denunciar la profundización del modelo neoliberal/neoextractivista y el racismo estructural en las vidas y territorios de las mujeres indígenas.

\section{Agradecimientos}

Este trabajo forma parte del proyecto de investigación: "Prácticas culturales de cuidado en mujeres indígenas de la región de Atacama, Chile" (2018-2019), financiado por la Vicerrectoría de Investigación y Postgrado de la Universidad de Atacama. A los/as evaluadores/as por sus valiosas contribuciones para enriquecer este escrito. Y nuestra enorme gratitud a las mujeres colla que nos dieron su confianza, cariño y nos abrieron las puertas de sus hogares y comunidades para contar sus saberes e historias de vida.

\section{Referencias Citadas}

Alarcón, A. y Nahuelcheo, Y.

2008 "Creencias sobre el embarazo, parto y puerperio en la mujer mapuche: conversaciones privadas". Chungara (Arica) 40 (2): 193-202.

Alcántara, G.

2008 "La definición de salud de la Organización Mundial de la Salud y la Interdisciplinariedad". Sapiens. Revista Universitaria de Investigación. 9 (1):93-107.

Arévalo, J.

2012 "El patrimonio como representación colectiva: La intangibilidad de los bienes culturales". Andes, (23).

Baeta, S.

2015 "Cultura y modelo biomédico: reflexiones en el proceso de salud-enfermedad". Comunidad y Salud 13(2):81-83.

Baeza, B.

2013 "La memoria migrante y la escucha de los silencios en la experiencia del parto en mujeres migrantes bolivianas en Comodoro Rivadavia (Chubut, Argentina)". Anuario Americanista Europeo 11(2): 179-197.

Bañuelos, N y Salido, P.

2007 "Consideraciones metodológicas para el diseño de propuestas de desarrollo local/regional sustentable en comunidades indígenas". Ra Ximhai 3(1):27-47. Universidad Autónoma Indígena de México Mochicahui, El Fuerte, Sinaloa.

Briceño-León, R.

2000 "Bienestar, salud pública y cambio social". En BriceñoLeón, R., De Souda, M, Coimbra, C (Coord.) Salud y equidad: una mirada desde las ciencias sociales (15-24). Rio de Janeiro. Editora Fiocruz.

Bonelli, C.

2015 "Trastornos ontológicos: pesadillas, fármacos psicotrópicos y espíritus malignos en el Sur de Chile". En
Tecnologías en los márgenes: antropología, mundos materiales y técnicas en América Latina (Colección Heterotopías, 4), Di Giminiani, P. González Varela, S. Murray, M y Risor, H (Eds.). México: Bonilla Artigas.

Cabnal, L.

2010 "Acercamiento a la construcción de la propuesta de pensamiento epistémico de las mujeres indígenas feministas comunitarias de Abya Yala". En Feministas siempre. Feminismos diversos: el feminismo comunitario. España: ACSUR-Las Segovias.

Castañeda, $M$.

2010 "Etnografía Feminista”. En Investigación Feminista: Epistemología, metodología y representaciones sociales, Blázquez, N. Flores, F. y Ríos, M.: 217-238. México: Universidad Nacional Autónoma de México.

Castañeda, M.

2019 "Perspectivas y aportes de la investigación feminista a la emancipación". En: Otras formas de (des)aprender: investigación feminista en tiempos de violencia, resistencias y decolonialidad 19-40. España: Hegoa.

Cardona-Arias, J.

2012 "Sistema médico tradicional de comunidades indígenas Emberá-Chamí del Departamento de Caldas-Colombia". Revista Salud Pública. 14 (4): 630-643.

Caroselli, S.

2013 "El dolor de los pacientes aymara de la comuna de Putre: prácticas terapéuticas y políticas de salud intercultural". Diálogo Andino (42):89-104.

Chávez, R., Arcaya, G., Garcia, T. e Infante, M.

2007 "Rescatando el autocuidado de la salud durante el embarazo, el parto y al recién nacido: representaciones sociales de mujeres de una comunidad nativa en Perú". Texto \& Contexto Enfermagem 16(4):680-687. 
Chávez, O y Carpio, C.

2018 "El reconocimiento del sistema indígena de salud. Implicaciones de la cobertura de salud gubernamental en México". Revista Latinoamericana de Bioética 18(2): 195-209.

Dias-Scopel, R., Scopel, D. y Langdon, E.

2017 “Gestação, parto e pós-parto entre os Munduruku do Amazonas: confrontos e articulações entre o modelo médico hegemônico e práticas indígenas de autoatenção". Ilha Revista de Antropología 19(1): 183-216.

Dides, C. y Pérez, M.

2007 "Investigaciones en salud sexual y reproductiva de pueblos indígenas en Chile y la ausencia de pertinencia étnica". Acta bioethica 13(2): 216-222.

Favret-Saada, J.

1990 Être Affecté, Gradhiva Revue d'Histoire et d'Archives de l'Anthropologie, (8): 3-9 (Traducción al español por Laura Zapata y Mariela Genovesi).

Gálvez, C.

2012 Conociendo la cultura Colla= Knowing the Colla Culture. Santiago de Chile: Consejo Nacional de la Cultura y las Artes.

Gleisner, C. y Montt, S.

2014 Colla: Serie introducción histórica y relatos de los pueblos originarios de Chile. Santiago de Chile: Fondo Nacional del Desarrollo de la Cultura y las Artes.

Goic, A.

2015 "Sistema de Salud de Chile: una tarea pendiente". Revista Médica Chile, (143): 774-786.

Gudemos, M.

2012 "Tu piel, mi piel, nuestra piel. Salud, música y naturaleza en Los Andes". Diálogo Andino, (39):9-22.

Gudynas, E.

2011 "Buen Vivir: Germinando alternativas al desarrollo". América Latina en movimiento. 462: 1-20.

Guerra, F.

2018 Proyectos mineros canadienses en el territorio del pueblo Colla, III Región de Atacama, Chile, Informe de impacto, Instituto Nacional de Derechos Humanos (INDH), Santiago de Chile.

Gundermann, $\mathrm{H}$.

2018 "Los pueblos originarios del norte de Chile y el Estado". Diálogo Andino, (55), 93-109.

Haraway, D.

1991 Ciencia, cyborgs y mujeres. La reinvención de la naturaleza. Madrid: Editorial Cátedra.

Hasen, $\mathrm{F}$

2012 "Interculturalidad en salud: Competencias en prácticas de salud con población indigena". Ciencia y enfermería, 18(3), 17-24.

Huanacuni, F.

2010 Buen Vivir/Vivir Bien. Filosofía, políticas, estrategias y experiencias regionales andinas. Perú: Coordinadora Andina de Organizaciones Indígenas (CAOI).
Instituto Nacional de Derechos Humanos (INDH)

2018 "Recursos naturales, empresas y derechos humanos. Análisis del impacto de actividades productivas sobre los recursos naturales y el medio ambiente". En Informe Anual: Situación de los Derechos Humanos en Chile 2018, 118165. Santiago de Chile: Instituto Nacional de Derechos Humanos (INDH).

Instituto Nacional de Derechos Humanos (INDH)

2019 Informe Misión de Observación, Copiapó y Tierra Amarilla, Región de Atacama. 17 al 20 de diciembre de 2018.

Jiménez, P., Hernández, A., Espinosa, M., Mendoza, G., y Torrijos, M.

2015 "Los saberes en medicina tradicional y su contribución al desarrollo rural: estudio de caso Región Totonaca, Veracruz". Revista Mexicana de Ciencias Agrícolas, 6(8):1791-1805.

Krippendorff, K.

1990 Metodología de análisis de contenido: teoría y práctica. Barcelona: Paidós Comunicación.

Leff, E., Argueta, A., Boege, E. y Porto, C.

2002 "Más Allá del Desarrollo Sostenible. La Construcción de una Racionalidad Ambiental para la Sustentabilidad: Una Visión desde América Latina". En Gonçalve Leff, E., Ezcurra, E., Pisanty, I. y Romero (comps.) La transición hacia el Desarrollo Sustentable. Perspectivas de América Latina y el Caribe. México: Universidad Autónoma Metropolitana.

Lorca, M. y Hufty, M.

2017 "El patrimonio como forma de resistencia a la gran minería: El caso del Huasco Alto, Chile". Intersecciones en antropología 18(1):31-42.

Mendoza, A., De León, R. Martínez, L., Chamorro, F., Chur, E.,

Rodríguez, F., Poveda, C., Flores, H. y Sandoval, I.

2013 "Inequidades en la salud sexual y reproductiva de las mujeres indígenas de Panamá. Revista Centroamericana de Obstetricia y Ginecología 18(1): 15-20.

Molina, R.

2014 "Marcas memorables en los relatos Collas de Atacama". Chungará (Arica) 46(4): 669-680.

Navarro, V.

1998 "Concepto actual de la salud pública". En Martínez, F, Castellano P.L, Navarro, V. Salud Pública. Ciudad de México, Editorial Mc Graw-Hill

Organización Panamericana de la Salud

s.f. La salud de los pueblos indígenas de las Américas: Conceptos, estrategias, prácticas y desafíos.

Ribeiro, D.

2018 "Breves reflexiones sobre Lugar de Enunciación". Relaciones Internacionales. Grupo de Estudios de Relaciones Internacionales. Universidad Autónoma de Madrid. 39:13-18.

Rivera Cusicanqui, S.

2018 Un Mundo Ch'ixi es posible. Ensayos desde un presente en crisis. Buenos Aires: Tinta Limón.

Rodríguez, V. y Duarte, C.

2018 "Experiencias y creencias de mujeres Colla de la región de Atacama". Cultura-hombre-sociedad 28(1):34-54. 